\title{
REDUCING HEALTH RISKS ARISING FROM CHILD AND ADOLESCENT LABOR
}

\author{
KINGA POLAŃSKA ${ }^{1}$, WOJCIECH HANKE ${ }^{1}$, ANDRZEJ BOCZKOWSKI ${ }^{2}$, and EWA WĄGROWSKA-KOSKI ${ }^{3}$ \\ ${ }^{1}$ Department of Environmental Epidemiology \\ ${ }^{2}$ Department of Health Policy \\ ${ }^{3}$ Out-Patient Clinic of Occupational Diseases
}

Nofer Institute of Occupational Medicine

Łódź, Poland

\begin{abstract}
Objectives: The aim of the study was to work out a program that would help develop the most effective methods for protecting the safety and health of young workers. Materials and Methods: The program was designed by a multidisciplinary team of experts in occupational and public health, occupational hygiene, health promotion, sociology, and regulatory and control activities. Results: The program points out the major aspects to be considered while implementing the existing legislation. The employers should have a proper recognition of health hazards related to working conditions at their enterprises. These should be considered while assessing work capability of adolescents during the pre-placement and periodic medical examinations. Prophylactic examinations for adolescent workers should be oriented towards the potential or existing health hazards and strenuous conditions of in-plant vocational training. It is essential to inform them about work-related health hazards and the preventive methods to be applied by both the workers themselves and the occupational health services. If a health problem or ailment is detected by an occupational physician, the adolescent worker should be referred to primary health care unit for further diagnostics. Conclusions: The most effective ways to protect the safety and health of young workers include a more accurate assessment of working conditions, contracting prophylactic examinations with only one occupational health service unit, providing appropriate risk information to adolescent workers/students, and a closer collaboration between school administration, employers and occupational health services.
\end{abstract}

Key words:

Adolescent, Labor, Work-related health hazards

\section{INTRODUCTION}

In adolescents, the effects of work on health and the physical, mental and intellectual development of an individual are different from those referring to adults. Accordingly, adolescent workers must be regarded as a specific risk group, and relevant measures must be taken to protect their safety and health. In Poland, like elsewhere in the European Union, a number of rules and regulations concerning both the principles of employment and working conditions protect employees from this age group against adverse health effects (1-6). A general assessment of com- pliance with these rules in Polish industrial plants is fairly good. The workplace survey report developed by the National Labour Inspectorate for 2004 revealed no particular cases of the employers' non-compliance with binding regulations on adolescent labor (6). Minor disobedience applied mainly to the procedure for documenting the employment of adolescent workers and incomplete coverage of adolescent workers by the pre-placement medical examinations. However, there was no single instance of adolescents performing the job prohibited by law to this age group (6).

This study was supported by the Word Health Organization under the Agreement for Performance of Work "Implementing the Children's Health and Environment Action Plan for Europe (CEHAPE) in the area of occupational health in Poland" (EUPOLPHE101RB04B).

Received: April 12, 2006. Accepted: June 1, 2006.

Address reprint requests to Dr. K. Polańska, Department of Environmental Epidemiology, Nofer Institute of Occupational Medicine, św. Teresy 8, 91-348 Łódź, Poland (e-mail: kinga@imp.lodz.pl). 
To gain insight into the actual working conditions of adolescent workers and to find out how they perceive their work and the related health hazards, we carried out a study among adolescent students at vocational schools who are subject to obligatory practical vocational training. Then a workshop was organized to work out a program that would help reduce the observed health hazards and develop the most effective methods to protect the safety and health of young workers. The workshop, supported by the WHO EURO, was hosted by the Nofer Institute of Occupational Medicine in Łódź, Poland.

\section{MATERIALS AND METHODS}

The first part of the study comprised a survey on health hazards encountered during vocational training at the technical schools in the Lódź district. In the second part, the results of our own survey as well as of workplace surveys performed by the District Labour Inspectorate in Łódź, made it possible to develop a program aimed at reducing health hazards and defining the most effective methods for health and safety protection.

\section{A survey on health hazards during vocational training in the Łódź district, Poland}

\section{Study design}

The case study was conducted on June 13, 15, and 18, 2005, at three vocational technical schools in Łódź. The schools rendered theoretical and practical training in electrical, mechanical and automotive professions. A self-administered questionnaire concerning the conditions and organization of work during practical training in industry was used as a basic research instrument.

\section{Study population}

Enrolled for the study were 16-18 years old (mean $17.2 \pm 0.6)$ students who had completed practical vocational training within a period of three months prior to the study. They agreed to take part in the project and were present at school activities on the days defined in the study protocol. The study population comprised 139 students: 58 (42\%) from electro-mechanical school, 21
(15\%) from general vocational school and 60 (43\%) from automotive school. As many as 95\% (132) of this population were male students, and female students made up only $5 \%$ (7).

\section{Questionnaire}

The questionnaire was developed by a multidisciplinary team of sociologists, epidemiologists and occupational physicians at the Nofer Institute of Occupational Medicine, Łódź. It comprised 38 close and open-end questions. The students responded anonymously to the questionnaire during their regular school classes in the presence, and when necessary, under the guidance of an interviewer. The respondents were also asked to provide socio-demographic data and information on their working conditions, with special regard to workplace accidents and injuries. We focused on the characteristics of work to be performed as vocational training, the training time, and the number and duration of breaks. We also intended to elicit information on the students' health condition and the presence and quality of pre-placement and routine medical examinations during the training.

\section{Workshop on "Reducing health risks arising from child and adolescent labor"}

On October 24-25, 2005, a workshop was organized at the Nofer Institute of Occupational Medicine to discuss the potential health hazards related to the work performed by children and adolescents. The objectives of the meeting were to design a program for reducing the hazards identified via the survey and to define the most effective methods for safety and health protection of young workers. A multidisciplinary team of specialists in occupational and public health, occupational hygiene, health promotion, sociology, and regulatory and control activities was established. The workshop was attended by 19 participants representing the Nofer Institute of Occupational Medicine, the Mother and Child Institute, regional divisions of the National Labour Inspectorate, the State Sanitary Inspectorate, regional occupational health centers, and the WHO Country Office in Poland. 


\section{RESULTS}

A survey on health hazards at vocational training in the

\section{Łódź district, Poland}

\section{General characteristics of vocational training}

As many as $82 \%$ of the students reported that the practical training corresponded with their vocational education, $4 \%$ presumed it was inconsistent, and $14 \%$ did not respond to this question. The work that the students had to carry out during vocational training was performed on every day of working week (about 16\%), on selected days of working week (58\%), once a week (23\%), or less frequently (3\%). Most of the students (90\%) reported working 4-8 h/day (mean $6 \mathrm{~h} 15 \mathrm{~min}$ ) and 7\% - 9 or more h/day. More than $90 \%$ of the students reported having breaks during a workday (78\% one break and 10\% two or more breaks). A 30-min break was reported by around 70\% of the students, but $14 \%$ pointed out shorter breaks (5-25 min) and $7 \%$ longer breaks (from $35 \mathrm{~min}$ up to $1 \mathrm{~h}$ ).

\section{Vocational and occupational safety and health (OSH) briefing}

Prior to the training, the majority (95\%) of the students received a general briefing on the job to be performed. This was conducted mostly by the teacher (57\%), but could also be done by an experienced worker (e.g., foreman) at the plant (33\%). However, $5 \%$ of the students did not report any briefing. Almost $93 \%$ of the students who received a theoretical briefing were given a demonstration of sample tasks. About $84 \%$ were taught how to avoid injuries and accidents at work. The training was conducted by teachers (52\%), experienced workers (37\%), or OSH instructors (4\%). Almost all the respondents reported that they had an opportunity to ask questions during the vocational training. These were addressed mostly to the teachers or the plant staff. About 9\% of the students denied they could ask questions while performing their job. About $32 \%$ of respondents took part in OSH training lasting $1 \mathrm{~h}, 33 \%$ had $2-4 \mathrm{~h}$ training and for $26 \%$ the training lasted more than $4 \mathrm{~h}$. It was interesting to find out how much this training helped them gain any new knowledge on occupational safety and health. About $7 \%$ of the students reported that almost everything was new to them, for $11 \%$ most of what was taught at the course was new, and $63 \%$ admitted that they had already known most of the issues discussed at the training course. The majority (73\%) of students reported that when performing their practical training they usually remembered what they had learned about the occupational safety and hygiene. However, about $7 \%$ of the students could not recall the contents of OSH training. For most (90\%) of the students, the work to be carried out as vocational training corresponded with their education and overall capabilities.

\section{Prevalence of workplace hazards as perceived by adolescent workers}

Jobs involving heavy physical effort are not permitted to adolescents. In our study, the workplace surveys indicated the absence of the heavy physical work component in the tasks to be performed by adolescent workers. However, about $17 \%$ of the respondents reported that their job required heavy physical effort, $61 \%$ medium and 21\% low. More than half of the students perceived their work as strenuous. Almost all of them (91\%) reported that they had not experienced or witnessed any workplace accident or injury, 5\% marked small injuries and $4 \%$ more serious accidents.

\section{Pre-placement examination}

About $73 \%$ of the students had a pre-placement medical examination before their training, $22 \%$ said they did not have that kind of examination, and 5\% did not remember whether or not they had had one. Most (70\%) of the examined students thought the examination was specific and thorough, but $26 \%$ expressed an opinion that it was general and superficial. More than $80 \%$ of the respondents regarded the examination as necessary and useful, and $17 \%$ thought it was unnecessary. Only $12 \%$ of the students admitted that they had a medical check-up during their vocational training, whereas the majority reported no medical examinations on the training.

\section{Workshop on "Reducing health risks arising from child and adolescent labor"}

The main conclusion reached at the Workshop was that the employer should have a proper recognition of the 
health hazards related to working conditions at the enterprise. These should be taken into consideration while assessing the work capability of adolescents during the pre-placement and periodic medical examinations. The prophylactic examinations for adolescent workers should be oriented towards potential or existing health hazards and strenuous conditions of in-plant vocational training. It is essential to inform the workers about work-related health risks and the preventive methods to be applied by both the workers themselves and the occupational health services. If a health problem or ailment is detected by an occupational physician, the adolescent worker should be referred to primary health care unit for further diagnostics. A draft proposal of a national program for reducing the health risks arising from child and adolescent labor was developed. The program points out the major aspects that should be considered while implementing the existing legislation. Adolescents involved in vocational activities can be classified into two groups: (a) adolescent workers and apprentice workers, and (b) vocational school students trained at school workshops and those on in-plant training. This dichotomy was taken into account while determining the organization and functions of the Polish system for protecting young workers. The draft is presented below.

The National Program on Reducing Health Risks Arising from Child and Adolescent Labor should cover the protection of both the adolescent workers and adolescent vocational students:

\section{(A) Protection of adolescent workers (including apprentice workers)}

1) Working conditions and the related health hazards should be assessed by the employer and clearly indicated in the medical request for a pre-placement examination of a candidate worker.

2) The employer should contract prophylactic care services with only one occupational health service unit. This would make it possible for the occupational physician to gain insight into the working conditions of an adolescent worker, which is essential for the quality of pre-placement and periodic examinations.
3) The pre-placement medical examination should be oriented towards specific health hazards and strenuous conditions of work to be performed by an adolescent worker (including in-plant verification of working conditions indicated by the employer).

4) The adolescent worker should be informed about the work-related health hazards and the methods used by the employer and occupational health service to reduce them.

5) A medical certificate specifying that the job to be taken up by an adolescent worker is not hazardous to health should be presented to the employer before the commencement of employment.

6) A training in occupational safety and hygiene should be organized by an authorized person.

7) Periodic medical examinations should follow the principles specified above for pre-placement examinations.

8) Primary care physician should be informed about the suspected health problems that need intervention.

\section{(B) Protection of adolescent vocational students who are} exposed to hazardous and strenuous conditions during vocational training at school workshops and in-plant training

1) It is proposed that the legislation on adolescent vocational students should be amended by introducing a provision on obligatory vocational guidance to be rendered by occupational health services in the final year of the secondary vocational school.

2) Vocational school should contract occupational health services with only one occupational health service unit.

3) Vocational training curriculum should include classes on selected issues concerning the prevention of work-related health hazards and promotion of healthy lifestyles and behavior.

4) Occupational physician should verify the working conditions indicated by the vocational school in its medical request for prophylactic examinations.

5) Prophylactic medical examinations should be oriented towards specific health hazards and strenuous conditions of work to be performed by an adolescent student 
on vocational training. If there is any health hazard, the student and his/her parents should be informed about the possible adverse health effects that may develop if the training is taken up or continued.

6) Primary care physician should be informed about the suspected health problems that need intervention.

\section{DISCUSSION AND CONCLUSIONS}

In Poland, there is a considerable interest in the scientific and regulatory issues concerning the protection of adolescent workers. The Polish law on the working conditions of young people, concordant with the Council Directive $94 / 33 / \mathrm{EC}$, is restrictive enough to ensure good protection for this population (1).

The compliance with these regulations on the part of employers appears to be relatively high. As revealed by the workplace survey reports submitted by regional divisions of the National Labour Inspectorate, no cases of severe violation of the law, in terms of adolescents' involvement in the jobs officially banned to this age group, could be found. The enforcement of regulations on adolescent labor and surveillance of working conditions as well as the promotion of activities for protecting young workers have resulted in a better recognition of the specificity of adolescent labor by both the employers and in-plant occupational health services.

The study carried out among adolescent students at vocational schools has provided us with abundant material indicating how these workers perceive their work and the related health hazards. Some shortcomings were found with respect to OSH training and medical examinations. More than $10 \%$ of the students reported that they had not participated in OSH training before they started working and more than half of the students who attended the training thought they had learned nothing new or useful. About $20 \%$ of the adolescents did not remember while working about the occupational health and safety issues. One-fifth of the students reported no pre-placement medical examinations prior to vocational training. Some of those who had been examined found the examination too general and superficial. Almost all the students expressed an opinion that the medical examinations before the training were necessary and useful. Moreover, they expected from the occupational physician a more thorough examination complemented with some kind of vocational guidance.

A panel of occupational medicine physicians and representatives of the State Sanitary Inspectorate and the National Labour Inspectorate outlined the most important aspects that should be considered while evaluating the conditions of child and adolescent labor in the Łódź district. They agreed that more effective solutions should be applied at each stage of preventive activities designed for adolescent workers and students of vocational schools. These include a more accurate assessment of working conditions, contracting prophylactic examinations with only one occupational health service unit, providing appropriate risk information to adolescent workers/students, and last but not least, a closer collaboration between school administration, employers, and occupational health services.

\section{ACKNOWLEDGEMENTS}

The authors appreciate the contribution of the multidisciplinary team of experts representing the Nofer Institute of Occupational Medicine, the Mother and Child Institute, the District Labour Inspectorate in Łódź, the State Sanitary Inspectorate, regional occupational health centers, and the WHO Country Office in Poland, to developing a draft proposal for the National Program on Reducing Health Risks Arising from Child and Adolescent Labor.

\section{REFERENCES}

1. Council Directive 94/33/EC of June 22, 1994 on the protection of young people at work. Off J L 216, 20.08/1994, p. 0012-20.

2. Adolescent employment Law of June 26, 1974. Uniform text with later amendments of February 8, 2005. J Law 2005;21 [in Polish].

3. Decree of the Council of Ministers of May 28, 1996 on the preparation of young people for employment and their wages and salaries. J Law 1996;6:278 [in Polish].

4. Regulation of the Ministry of Labour and Social Policy of December 5, 2002 on the conditions of exceptional employment of adolescents under 16 years of age who have completed secondary educa- 
tion and those who have not completed secondary education. J Law 2003;214:1808 [in Polish].

5. Directive of the Council of Ministers of August 24, 2004 on the list of jobs not allowed for adolescents and the conditions of their employment at some of the jobs. J Law 2004;200:2047 [in Polish].
6. Public Information Bulletin issued by the National Labour Inspectorte [cited 2006 April 24]. Available from: http://www.bip. pip.gov.pl/pl/bip.px_spr_gip_04_rozdz_04b.pdf. 